\title{
Kant e a liberdade prática na Crítica da Razão Pura
}

\author{
Kant and the practical freedom in the Critique of Pure Reason
}

\begin{abstract}
Alcino Eduardo Bonella
Doutorado em Filosofia pela Universidade Estadual de Campinas (Unicamp), professor associado de Filosofia na Universidade Federal de Uberlândia (UFU), pesquisador do CNPq, Uberlândia, MG - Brasil, e-mail: abonella@gmail.com
\end{abstract}

\section{Resumo}

Kant estruturou sua filosofia de modo a manter a possibilidade de afirmarmos que somos seres pertencentes ao mundo sensível e, enquanto tais, termos todos os nossos comportamentos explicados de um modo natural; todavia, ele também sustentou que somos seres com uma capacidade racional de representação de um dever ser do mundo, capacidade que nos permite termos todas as nossas decisões avaliadas de uma maneira que independe de como o mundo realmente é. Neste trabalho, examinaremos a posição de Kant em alguns textos da primeira Crítica em que se diferencia a liberdade transcendental, ou liberdade como espontaneidade, da liberdade prática entendida como livre-arbítrio, que pode se determinar por representações da razão. Com base nos textos e em comentários de Allison (1982), veremos que a liberdade em sentido prático é diferenciada da liberdade em sentido cosmológico, sendo, por um lado, compatível com o determinismo das causas naturais, que opera com a explicação dos fenômenos (e o livre-arbítrio humano não deixa de ser também um arbítrio sensitivo); mas, por outro lado, a concepção de Kant mantém ou subsume uma noção comum de liberdade humana, aquela da deliberação e decisão responsável, já que o livre-arbítrio não será 
patologicamente determinado por motivos sensíveis imediatos. "A questão em torno da liberdade transcendental concerne unicamente ao saber especulativo, e podemos pô-la de lado como totalmente indiferente quando estamos à volta com o [problema] prático" (CRP B 831-832).

Palavras-chave: Kant. Liberdade. Razão pura. Razão prática. Crítica.

\section{Abstract}

Kant structured his philosophy as to be possible for one to affirm we are beings that are part of the sensitive world and, as such, have all of our behaviors naturally explained. However, he also supported that we are beings with a rational capacity for representing how the world ought to be, and this rational capacity allows us to have all our decisions accessed in a way that is free from how the world actually is. In this paper we examine Kant's view in certain texts of the first Critique where he differentiates transcendental freedom (or freedom as spontaneity) from practical freedom, understood as free-will, one that can determine itself by representation of reason. Based on these texts and on some of Allison's commentaries (1982), we will see that freedom, in a practical sense, is differentiated from freedom in a cosmological sense, being on one hand compatible with the determinism of the natural causes that operates with the explanation of phenomena (and the human will is a kind of sensitive arbitrium); On the other hand, Kant's conception maintains or subsumes a common notion of human freedom as deliberation and accountable decision - in a sense that it would not be pathologically determined by sensitive immediate motives. "The issue round transcendental freedom concerns uniquely to speculative knowledge, and we can put it aside when dealing with the practical [issue]" (CPR B 831-832).

Keywords: Kant. Freedom. Pure reason. Practical reason. Critique.

Alguns aspectos essenciais da discussão filosófica sobre a liberdade podem ser apreendidos no seguinte panorama apresentado por Watson (1985, p. 179):

A ideia básica é que a liberdade requer a habilidade de agir de outra maneira, sendo que o determinismo exclui isto: (1) se o determinismo é verdadeiro, então toda ação é causalmente necessária; (2) se toda ação 
é causalmente necessária, então nós nunca podemos agir de outra maneira que a que agimos; (3) se nós nunca podemos agir de outra maneira, então nós não somos agentes livres; (4) assim, se o determinismo é verdadeiro, nós não somos agentes livres; (5) se nós não somos agentes livres, então nós não somos responsáveis por nossas ações. [...] O compatibilista deve rejeitar (2) ou (3).

Uma alternativa sugerida por Watson é a que rejeita que a ação humana possa ser apreendida coerentemente a partir da noção de lei causal. Considerando que na explicação da ação humana entram em cena razões e intenções, uma coisa seria explicar o comportamento natural, outra bem diferente seria tornar a ação inteligível em termos de normas de racionalidade e de contexto social. Isso ainda é uma forma de compatibilismo porque aceita que a psicologia comportamental possa ser determinística, ou, em outros termos, que o determinismo natural continue sendo uma tese verdadeira, ainda que não se assuma que a compreensão da ação humana se esgota nessa redução, o que mantém em aberto um lugar para a crença na liberdade e responsabilidade dos seres humanos. Se essa variação dita por Watson pertencer ao século 20 e aos que são influenciados por Wittgenstein, uma formulação clássica dessa posição pode ser encontrada já em Kant. De fato, uma das notas distintivas do gênio kantiano e ao mesmo tempo, um dos pontos que mais levanta dúvidas e incompreensões ${ }^{1}$, é a sua forma de compatibilizar determinismo natural e liberdade moral.

Se pensamos que a explicação de um certo comportamento humano repousa na liberdade de sua vontade, talvez estejamos considerando algo parecido com o que encontramos na seguinte passagem do texto de Kant (CRP, B 478):

se agora me levanto da minha cadeira de modo inteiramente livre e sem a influência necessariamente determinante das causas naturais, então nesse evento inicia-se absolutamente uma nova série [de eventos] juntamente com as suas consequências naturais até o infinito [...].

1 Cf. Wolff 1986; WALKER, R. Kant. New York: Routledge, 1999; 0'NEILL, 0. Kantian ethics. In: SINGER, P. A companion to ethics. Oxford, Blackwell, 1994. p. 175-185. 
Esse é um exemplo da ideia de liberdade transcendental que, segundo Kant, é pressuposta por aquele que não admite o determinismo universal e, ao lado das causas naturais, admite uma causalidade mediante a liberdade. Para ele, o princípio do determinismo implica na razão insuficiente de cada evento tomado em si mesmo, que precisa ser explicado por um outro evento anterior e assim sucessivamente, sob pena de não ser inteligível, ao mesmo tempo em que implica, logicamente, que há uma causa para qualquer evento, sugerindo uma razão para a existência da série de causas encontradas. Segundo Kant, para o defensor desta tese,

tem que ser admitida uma espontaneidade absoluta das causas, que dê início de si a uma série de fenômenos precedentes segundo leis da natureza, por conseguinte, uma liberdade transcendental, sem a qual mesmo no curso da natureza a série sucessiva dos fenômenos do lado das causas não é jamais completa (B 474).

A concepção de liberdade como espontaneidade ou de liberdade transcendental não é exatamente a de Kant. Ele a coloca como necessária para o metafísico que nega o determinismo universal das causas naturais, mas a posição diametralmente oposta, como antítese disto, se baseia também na noção de causalidade. Kant está explicitando a antinomia da razão quando esta aplica a categoria de causalidade a objetos que estão para além da experiência possível.

No caso da liberdade, o defensor da antítese sustentaria então que "não há liberdade alguma, mas tudo no mundo acontece meramente segundo leis da natureza" (B 472). Se, para nos libertarmos da coerção das leis causais, admitimos algo como uma liberdade transcendental ou uma liberdade como espontaneidade, então nos afastamos também da inteligibilidade dos eventos. Não temos mais como garantir uma unidade na percepção e explicação dos fenômenos, pois a liberdade como espontaneidade é a ausência de determinação. Para o que defende esta posição,

a ilusão da liberdade [...] promete paz ao entendimento inquiridor na cadeia das causas enquanto o conduz a uma casualidade incondicionada 
que começa a agir de si, mas que, por ser ela mesma cega, rompe o fio condutor das regras, pelo qual é possível uma experiência completamente coerente (B 475).

Mesmo se concedesse que tal espontaneidade absoluta fosse necessária para dar paz ao intelecto, que não se conformaria com a infinita necessidade de uma causa anterior para os eventos, o que estaríamos fazendo é supor uma liberdade para iniciar as mudanças do mundo, ou seja, algo extrínseco a ele. Isso já por si é temerário de fazer (pois não temos nenhuma intuição possível de tal objeto além da experiência), mas, mesmo se fosse aceito, em nada nos autorizaria atribuir às substâncias no mundo, essa faculdade transcendental,

porque neste caso desapareceria na maior parte a interconexão dos fenômenos determinando-se mútua e necessariamente segundo leis universais - conexão que se chama natureza - e com ela desapareceria o critério da verdade empírica, que distingue a experiência do sonho. Com efeito, [...] é difícil pensar ainda a natureza, porque as leis desta seriam modificadas incessantemente pelas influências da liberdade e o jogo dos fenômenos, que segundo a simples natureza seria regular e uniforme, tornar-se-ia assim confuso e desconexo (B 479).

Esta é a análise da liberdade no sentido cosmológico (cf. B 560), ou seja, no sentido teórico da possibilidade de uma liberdade transcendental como espontaneidade absoluta para preencher a cadeia causal. Kant pensa que soluciona a aparente antinomia com sua distinção entre fenômenos e coisas em si mesmas. A categoria de causalidade só possui aplicação concreta quando limitada aos objetos da sensibilidade. Apenas se esses objetos também fossem a realidade em si mesma, apenas se os limites com que apreendemos os fenômenos, como por exemplo, o limite da temporalidade, presente em nosso sentido interno, também fossem necessários na realidade das coisas em si mesmas, é que, então, o metafísico racionalista perderia totalmente a batalha para o metafísico empirista. Mas, como a suposição dogmática de que as coisas em si mesmas sejam exatamente como aparecem em nossos limites experimentais, também está além da experiência possível, 
permanecendo especulativa, não podemos estender a determinação pelas leis naturais, ou seja, o determinismo, a tudo, eliminando dogmaticamente a possibilidade da liberdade como espontaneidade. Ela, porém, permanece como uma especulação da razão e, também, não pode ser demonstrada. Teoricamente, não podemos conhecer o mundo sem pressupor o determinismo e sem eliminar a liberdade como espontaneidade da análise dos fenômenos. Também não podemos negar a possibilidade de que exista a liberdade, tanto de uma substância como causa primeira do mundo, um deus iniciador do mundo, quanto de substâncias dentro do mundo, como dos seres humanos, tomados como coisas em si. Mas, se a metafísica não pode ser solucionada, por que permanece desde o início e por que temos tanto interesse em suas questões? A resposta de Kant nos remete ao seu conceito de liberdade prática. Ou seja, além da compreensão, esquematizada anteriormente, sobre a liberdade em sentido teórico, Kant apresenta uma concepção de liberdade humana que, nos textos da Crítica da Razão Pura que estamos analisando, aparece da seguinte maneira.

Na Dialética Transcendental da primeira Crítica Kant escreve:

A liberdade no sentido prático é a independência do arbítrio da coerção por impulsos da sensibilidade. Com efeito, um arbítrio é sensível na medida em que é afetado patologicamente (por motivações da sensibilidade); denomina-se animal (arbitrium brutum) quando ele pode ser patologicamente necessitado. $\mathrm{O}$ arbítrio humano é na verdade um arbitrium sensitivum mas não brutum e sim liberum, pois ao homem é inerente uma faculdade de determinar-se por si mesmo, independente da coerção por impulsos sensíveis (KANT, 1987, 102; [B 562]).

O ser humano se representa, por meio da faculdade da razão, certos imperativos que ele se impõe. Esta representação permanece totalmente no grau das ideias, e não há como observarmos empiricamente esta motivação a partir de representações da razão.

Em consequência, a moralidade própria das ações (mérito e culpa), mesmo a de nosso próprio comportamento, permanece totalmente oculta. As nossas responsabilidades só podem ser referidas ao caráter 
empírico. Mas quanto disto se deve imputar ao efeito puro da liberdade, quanto à simples natureza e quanto ao defeito de temperamento do qual não se é culpado, ou à natureza feliz (merito fortunae) do mesmo, eis algo que ninguém pode prescrutar e, consequentemente, também não [pode] julgar (richten) com toda a justiça (KANT, 1987, 109, nota [B 579 , nota $])^{2}$.

No Cânone da razão pura, na mesma obra, Kant sustenta a mesma concepção de liberdade humana. O arbítrio é puramente animal quando é patologicamente determinado. Quando pode ser determinado também por motivações que só podem ser representadas pela razão, chama-se livre-arbítrio. Novamente aqui se explicita que o uso da razão pode nos fazer representar o que seria bom e útil, e isto só se entende como imperativo acerca do que deve ocorrer na nossa ação, daí Kant utilizar o nome de leis práticas para tais representações. Essas leis regem um mundo, mas um mundo moral, que, enquanto ideia, permanece inacessível aos nossos sentidos. Da mesma maneira que, na Dialética, a representação que nos move como seres livres não pode ser demonstrada empiricamente, ou seja, ela permanece, do ponto de vista teórico, especulativa. E na teoria, para o mundo sensível do que ocorre de fato (para os fenômenos), continua valendo o mais estrito determinismo. Como se diferencia então a liberdade transcendental, ou liberdade como espontaneidade, da liberdade prática, ou liberdade como livre-arbítrio, que é sensível, mas também pode se determinar por representações da razão?

A resposta de Kant, grosso modo, e circunscrevendo-nos aos textos da primeira Crítica que ora utilizamos, pode ser assim resumida: quando se trata da última, ou seja, da liberdade prática, deve-se colocar de lado o problema especulativo da liberdade transcendental, que não pode ser pressuposta como fundamento explicativo dos

\footnotetext{
2 Podemos comparar esse ceticismo quanto à realidade da motivação pela razão, com os 10 primeiros parágrafos da segunda seção da Fundamentação da Metafísica dos Costumes, um dos textos privilegiados para se compreender a tese kantiana de que o dever não é um conceito empírico. Lá se encontra, no parágrafo dois, por exemplo, que "é absolutamente impossível encontrar na experiência com perfeita certeza um único caso em que a máxima de uma ação, de resto conforme ao dever, se tenha baseado puramente em motivos morais e na representação do dever. [...] nunca podemos penetrar completamente até aos móbiles secretos dos nossos atos, porque, quando se fala de valor moral, não é das ações visíveis que se trata, mas de seus princípios íntimos que se não veem".
} 
fenômenos, ainda que sua realidade permaneça um problema para a razão (cf. KANT, 1987, p. 221; [B 829]). Já a liberdade prática, por um lado, é compatível com o determinismo das causas naturais, já que o determinismo se aplica na elucidação dos fenômenos, e o livre arbítrio humano não deixou de ser um arbítrio animal, ou seja, um arbítrio sensível ou sensitivo. Mas, por outro lado, a liberdade prática mantém ou subsume uma noção comum de liberdade humana, aquela da deliberação e decisão responsável, já que esse livre-arbítrio, ainda que seja afetado pela sensibilidade, não está determinado exclusivamente por motivos sensíveis imediatos. Kant mantém, de um modo impressionante, a possibilidade de dizer que somos seres pertencentes ao mundo sensível e, enquanto tais, temos todos os nossos comportamentos explicados de um modo natural. Mas também somos seres de tal modo complexos, com uma capacidade reflexiva de representação de um dever ser no mundo, que nos permite que todas as nossas decisões possam ser avaliadas de uma maneira que independe de como o mundo realmente é. No final das contas, são as mesmas as ações que estão sendo consideradas, ora como decisões livres que aparecem na ordem da razão, ora como comportamentos ou eventos que aparecem na ordem dos fenômenos. É claro que isso só é possível se pensamos que, quando resistimos a certas inclinações sensíveis para seguir nosso dever, não estamos realmente impondo ao curso dos eventos e das causas naturais de nosso comportamento algum tipo de intervenção espontânea de uma vontade abstrata e arbitrária. Nós realmente deliberamos e decidimos, representando o que é bom e útil, ou o que é nosso dever, mas essa deliberação e decisão ainda são atividades de um ser sensível, que faz parte da natureza. O ser humano não é patologicamente determinado, como outros animais, mas isso significa apenas que tal capacidade de resistência às inclinações sensíveis inexiste nestes últimos, enquanto que, nos seres humanos, há a experiência de dominar "as impressões que incidem sobre nossa faculdade sensível de desejar mediante representações daquilo que, mesmo de um modo mais remoto, é útil ou prejudicial" (KANT, 1987, [B 830]). Ou seja, há um arbítrio que é patologicamente afetado por motivações sensíveis, e que é praticamente livre por ser motivado pela razão. Mas ainda é o arbítrio de um ser vivo. 
O núcleo da concepção que tentamos brevemente descrever e comentar pode ser encontrado na seguinte citação de Kant (1987, p. 222; [B 831-832]):

se mesmo naquelas ações mediante as quais prescreve leis a razão não é por sua vez determinada por outras influências, e se isto que, com respeito aos impulsos sensíveis, se chama liberdade não consiste, no que se refere a causas eficientes mais elevadas e mais remotas, por sua vez em natureza, não nos interessa no campo prático [grifo meu]. Aqui perquirimos a razão inicialmente com vistas à prescrição do comportamento e aquela questão é de caráter meramente especulativo, podendo ser posta de lado na medida em que o nosso propósito se dirige para o fazer ou o deixar de fazer. Conhecemos, pois, a liberdade prática pela experiência como sendo uma das causas naturais, a saber, uma causalidade da razão na determinação da vontade; enquanto isso, a liberdade transcendental exige uma independência desta mesma razão [...] permanecendo pois um problema. Só que este problema não pertence à razão em seu uso prático. [...] A questão em torno da liberdade transcendental concerne unicamente ao saber especulativo, e podemos pô-la de lado como totalmente indiferente quando estamos à volta com o [problema] prático.

Considerando o debate contemporâneo, pode-se sugerir que há em geral uma concepção inflada de liberdade (ou de autonomia), que não é necessária de ser assumida, e que, enquanto tal, pode ser vista como refutada ou ao menos enfraquecida pela ciência atualmente disponível, pela neurociência, por exemplo, mas ainda há como se ter uma concepção naturalista de livre-arbítrio e de autonomia e que encontramos, bem compreendida, tal concepção na filosofia da Kant: por exemplo, em termos atuais, basta que nossa noção de determinação natural da ação deixe algum espaço para o imput-responsiveness possível dos grandes primatas sociais que somos, respondendo inteligentemente ao ambiente natural e social (moral) que nos cerca. Tal capacidade de resposta inteligente é, grosso modo, nossa liberdade prática, e não é necessário inflarmos o conceito de agente livre, tratando-o como indeterminado ou como aquele que determina a ação por meio de um ego metafísico. Esse 
simplesmente não é o melhor conceito de liberdade, que poderia ainda ser o de simples determinação da intenção por um self cerebral primata paradigmático, ou seja, exatamente, pelo sistema neural impulsivo-cum-reflexivo da espécie.

Este artigo tentou mostrar que Kant não defendeu o indeterminismo ou um ego metafísico separado das determinações naturais. Será que, se nós desinflarmos a concepção tradicional de liberdade, ou seja, retirarmos ou enfraquecermos expressões como "livre de influência", "absoluta responsabilidade", "totalmente consciente", "controle sobre ação", "indeterminada" etc., não restaria uma concepção mais bem ponderada e de fácil compatibilização com o determinismo natural?

Não se trata então de negar a determinação ou influência causal de fatores os mais variados possíveis (desejos de primeira ordem, recompensas e desprazeres instintivos, pré-determinação neural, pressão ambiental e social etc.), mas, aceitando-as, ainda assim, explicitar a presença da liberdade (relativa) em seres como os humanos (desejos de segunda ordem reorientando as primeiras, capacidade de revisão de opiniões morais e sociais, formação racional de intenções, flexibilidade adaptativa), seja (i) pela natureza complexa daqueles fatores causais (as próprias influências) entre si (os desejos de primeira ordem ainda são desejos dos seres humanos e não de outros seres, são como que prova de que o controle, ou parte dele, está conosco), seja (ii) pela interação das influências com o aparato cerebral humano complexo (i e ii indiciando uma flexibilidade ambiental e a multiplicidade de deliberações e ações disponíveis no meio cultural como sinal ou prova de uma liberdade natural "evoluída"), seja (iii) pelo feedback ou resposta ativa do aparelho cerebral ou parte dele - a parte reflexiva - e social humano ao meio ambiente que o influencia.

Liberdade ou Autonomia pode ser o nome para tal capacidade de (i) exercer controle sobre certas de nossas intenções e ações, e (ii) de sermos relativamente responsáveis por nossos atos e escolhas. Para refutar ou questionar tal concepção parece que é preciso mostrar que nunca temos controle em nenhum dos casos e que nunca somos sequer 
relativamente responsáveis por nossas escolhas, mas parece que tal hipótese não seria naturalisticamente muito razoável ${ }^{3}$.

\section{Referências}

ALLISON, H. E. Practical and transcendental freedom in the critique of pure reason. Kant-Studien, v. 3, n. 2, p. 271-290, 1982.

KANT, I. Crítica da razão pura. São Paulo: Nova Cultural, 1988.

KANT, I. Fundamentação da metafísica dos costumes. São Paulo: Abril Cultural, 1980.

KANT, I. Critique of practical reason. New York: Liberal Arts, 1956.

SCHNEEWIND, J. B. Autonomy, obligation and virtue: An overview of Kant's moral philosophy. In: GUYER, P. The Cambridge companion to Kant. Cambridge: Cambridge University Press, 1992. p. 309-341.

DENNETT, D. C. A liberdade evolui. Lisboa: Temas e Debates, 2003.

TAYLOR, R. Liberdade e determinismo. In: TAYLOR, R. Metafísica. Rio de Janeiro: J. Zahar, 1969. p. 53-79.

O'NEILL, O. Constructions of reason. Cambridge: Cambridge University Press, 1995.

O'NEILL, O. Kantian Ethics. In: SINGER, P. A companion to ethics. Oxford: Blackwell, 1994. p. 259-269.

RODHEN, V. Interesse da razão e liberdade. São Paulo: Ática, 1981.

WALKER, R. Kant. New York: Routledge, 1999.

3 Também haveria ainda, penso eu, espaço para uma noção de responsabilidade pessoal cuja ênfase recaia na maior ou menor pessoalidade envolvida na agência, ou seja, algo que assumisse que não somos realmente livres, mas que ainda podemos nos ver pragmaticamente como tais, como causas de certas intenções de ações, e, nesse sentido, sermos responsabilizados moral e socialmente. 
WATSON, G. Free Will. In: KIM, J.; SOSA, E. A companion to metaphysics. Oxford: Blackwell, 1995. p. 175-182.

WOLFF, R. P. The First Critique Background of the Groundwork. In: WOLFF, R. P. The Autonomy of Reason: a commentary on Kant's groundwork of the Metaphysic of Morals. Gloucester: Peter Smith, 1986. p. 5-24.

Recebido: 05/09/2011

Received: 09/05/2011

Aprovado: 23/01/2012

Approved: 01/23/2012 